\title{
A comparison of concurrent chemoradiotherapy and radiotherapy in Chinese patients with locally advanced cervical carcinoma: a multi-center study
}

Zhijie Li, Shuyan Yang, Lei Liu and Shiyu Han ${ }^{*}$

\begin{abstract}
Background: We investigated the efficacy of concurrent chemoradiotherapy (CCRT) over radiotherapy (RT) in Chinese patients with locally advanced cervical carcinoma.

Patients and methods: Between January 2005 and January 2008, 192 patients with squamous cell carcinoma of the cervix were included in the study: 96 in arm A (CCRT with $20 \mathrm{mg} / \mathrm{m}^{2}$ cisplatin for 5 days) and 96 in arm B (RT). The overall response rate was the primary endpoint. The secondary endpoints included overall survival, progression-free survival, and toxicity.
\end{abstract}

Results: The 5-year overall response rate was 67\% and 53\% for the CCRT and RT arms, respectively, and the difference was statistically significant, while the median overall survival was 68 months (range 3-85 months) and 61 months (range 4-83 months), respectively $(P=0.009)$. In addition, the median progression-free survival for CCRT was 62 months (range 3-83 months), whereas it was 51 months (range 4-81 months) for the RT arm $(P=0.025)$. The toxicity profile, both acute and late, was comparable in both arms.

Conclusion: In summary, we demonstrate that CCRT was effective and better tolerated than RT alone in Chinese patients with locally advanced cervical carcinoma.

Trial registration: Chinese Clinical Trials Register: ChiCTR-TRC-13003979.

Keywords: Advanced cervical carcinoma, Concurrent chemoradiation, Radiotherapy

\section{Introduction}

Cervical carcinoma is an important cause of cancer-related death in women in developing countries, and thus, continues to pose a major threat to their health $[1,2]$. It is the commonest malignancy among women in China and is widely prevalent all over the country. The 5 -year overall survival rate mainly depends on the stage of the tumor $[3,4]$. It varies from $98 \%$ in early stage disease to $10 \%$ in the most advanced stages [5]. In the last decade, survival has improved due to the development of new treatment strategies such as the combination of chemotherapy and radiation [6,7].

Currently, a number of treatment options for patients with cervical carcinoma are available, including surgery

\footnotetext{
* Correspondence: hanshiyu0451@163.com

Department of Gynaecology and Obstetrics, Fourth Affiliated Hospital of Harbin Medical University, No.37 Yiyuan Street, Nangang District, Harbin, Heilongjiang Province 150001, China
}

(C) 2014 Li et al.; licensee BioMed Central Ltd. This is an Open Access article distributed under the terms of the Creative Commons Attribution License (http://creativecommons.org/licenses/by/4.0), which permits unrestricted use, distribution, and reproduction in any medium, provided the original work is properly credited. The Creative Commons Public Domain Dedication waiver (http://creativecommons.org/publicdomain/zero/1.0/) applies to the data made available in this article unless otherwise stated.
[8,9]; radiotherapy $[10,11]$; chemotherapy such as carboplatin [12], cisplatin [13], paclitaxel [14], topotecan [15], gemcitabine [16], docetaxel [17], ifosfamide [18], 5-fluorouracil (5-FU) [19], irinotecan [20], mitomycin [21], and bevacizumab [22]; and hyperthermia [23], either as a single or combined modality [24,25], wherein the choice of treatment aims at achieving the best results with the least morbidity.

Until 1999, the primary treatment for locally advanced cervical carcinoma was radiotherapy, where the tolerance of normal tissues limits the dose intensity $[5,26]$. Recently, the results of a number of clinical trials have shown that concurrent chemoradiotherapy (CCRT) provides higher cure rates than radiotherapy alone [27-29]. Therefore, CCRT is now considered standard treatment for patients with tumors in stage IIB or higher [30,31]. However, there is inadequate data about the efficacy and safety of CCRT in Chinese patients with locally advanced cervical 
carcinoma. Therefore, the primary aim of this randomized study was to prove the superiority of CCRT over radiotherapy (RT) alone in terms of survival, failure rate, and toxicity.

\section{Patients and methods}

Between January 2005 and January 2008, 192 patients with a pathological diagnosis of stage IIB-IIIB squamous cell carcinoma of the cervix as per the International Federation of Gynecology and Obstetrics (FIGO) criteria, were recruited to participate in this study. To be eligible, patients had to be between the ages of 20 and 65 years, with a Karnofsky performance status $\geq 70$, hemoglobin $\geq 10 \mathrm{~g} / \mathrm{dL}$, leukocyte count $\geq 3000 / \mathrm{mm}^{3}$, absolute neutrophil count $\geq 1500 / \mathrm{mm}^{3}$, platelets $\geq 100,000 / \mathrm{mm}^{3}$, creatinine clearance $\geq 50 \mathrm{~mL} / \mathrm{min}$, and normal liver function test results. In addition, informed consent documents were signed by the patients. Patients with nonsquamous histology, para-aortic lymph nodes, distant metastases, or synchronous/metachronous malignancy were excluded. The study was approved by the institutional ethics committees of Third Affiliated Hospital and the Fourth Affiliated Hospital of Harbin Medical University with permission number (KY2005-01 and RR2004-12).

The randomization code was generated using a computerized number generator through the stratified block randomization method of the SAS package (SAS Institute Inc., Cary, North Carolina, USA) by a statistician with no clinical involvement in this trial. After qualifying, patients were assigned to 2 treatment arms: CCRT (arm A) or RT (arm B) by investigators at each center. The allocation was concealed in sequentially numbered, opaque, sealed envelopes containing the randomization assignments. In addition, all the outcome assessors and data analysts were blinded in this study.
The plan was to conduct the research in the Third Affiliated Hospital and the Fourth Affiliated Hospital of Harbin Medical University. In preparing for this research, we identified that these 2 centers had offered CCRT or RT treatment to 192 patients between January 2005 and January 2008. The individuals who were accepted for CCRT and RT were informed about the research and given an information sheet and signed informed consent. After the clinical assessment, patients were randomized to receive CCRT or RT, which was delivered by fully qualified therapists.

The treatment schedule consisted of external-beam $\mathrm{RT}$ to the pelvic region delivered with $15-\mathrm{MV} \mathrm{X}$-rays. Pelvic radiation was given in daily fractions of 2 Gy for 5 days/week with a four-field technique (anterior and posterior portals: $0.6 \mathrm{~Gy}$, lateral portals: $0.4 \mathrm{~Gy}$ ), up to a total dose of $46 \mathrm{~Gy} / 23$ fractions. The upper border of the pelvic portal was at the L4-L5 junction. The lower border was at the lowest part of the obturator foramen, which was modified according to the vaginal extent of the disease. The lateral borders were kept $1.5-2 \mathrm{~cm}$ lateral to the bony pelvis. When the four-field box technique was used, the anterior or posterior borders of the lateral portals were kept at the cortex of the pubic symphysis and in the middle of the $\mathrm{S} 2$ vertebrae, respectively, and verified with a computed tomography (CT) scan with markers and extended posteriorly, if needed.

A cervical boost was given using the X-ray arch technique or high-dose-rate (HDR) intracavitary brachytherapy at a total dose of 10 Gy. Brachytherapy was conducted using an iridium-192 source and consisted of 2 separate endocavitary insertions, with an interval of at least $48 \mathrm{~h}$, with the help of Fletcher-Suit after-loading applicators (Radium Chemical Company, New York, USA) and vaginal cylinders. As per the recommendations of the International

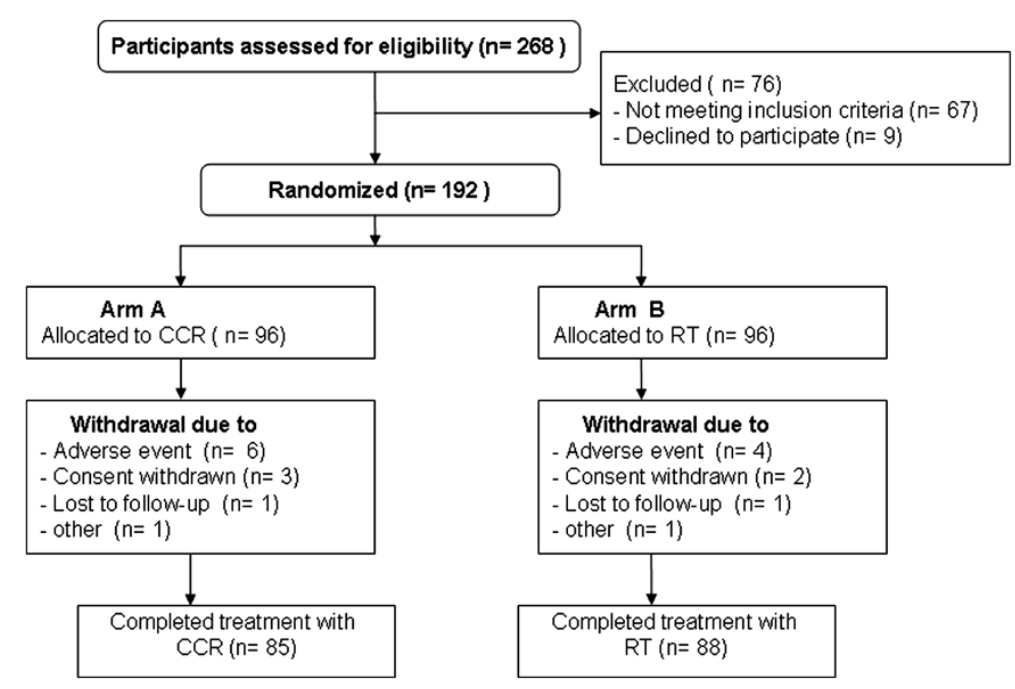

Figure 1 Flow of participants through trial. 
Commission on Radiation Units and Measurements (ICRU 38), orthogonal films (at $45^{\circ}$ and $315^{\circ}$ ) were taken to verify the placement of the applicators, to evaluate doses, and to deliver the dosimetric plan. Acceptable doses for the bladder and rectum were equivalent to $75 \%$ and $70 \%$, respectively, of the dose received at point A on the radiographs; manual and graphic optimization was allowed.

In addition to RT, patients in the CCRT arm also received $20 \mathrm{mg} / \mathrm{m}^{2}$ cisplatin for 5 days, at 21-day intervals for a total of five cycles.

All measurable lesions were evaluated for tumor response according to the Response Evaluation Criteria in Solid Tumors (RECIST 1.0) [32]. All radiological assessments were confirmed by extratumoral reviews. Toxicity was graded according to the National Cancer Institute Common Toxicity Criteria for Adverse Events (AEs) (CTCAE) version 3.0 [33].

An intention to treat analysis was performed. Sample size was calculated with an expected 15\% difference between the 2 arms. Overall survival was calculated from the day of randomization to the day of death. Data on patients who were alive were censored on the date on which they were last known to be alive. Relapse-free survival was computed from the date of randomization to the date of relapse, death or completion of follow-up, whichever occurred first. Data on patients who were alive and relapse-free were censored at the time of the last follow-up visit. Overall survival and relapse-free survival rates were calculated by the Kaplan-Meier method and a $P \leq 0.05$ was considered statistically significant. All $P$ values were obtained from 2 -tailed t-tests.

\section{Results}

In this study, 268 participants were initially screened. Of these 268 patients, 76 subjects were excluded. Of these 76 patients, 67 did not meet study criteria, and 9 declined to
Table 2 Summary of adverse events

\begin{tabular}{lll}
\hline Adverse events & $\mathbf{C C R}(\mathbf{n}=\mathbf{9 6})$ & $\mathbf{R T}(\mathbf{n}=\mathbf{9 6})$ \\
& $\mathbf{G 3 / 4}(\geq \mathbf{G 3})(\%)$ & $\mathbf{G 3 / 4}(\geq \mathbf{G 3})(\%)$ \\
\hline Leukopenia & $8 / 3(11 \%)$ & $4 / 3(7 \%)$ \\
Thrombocytopenia & $2 / 0(2 \%)$ & $0 / 0(0 \%)$ \\
Nausea & $4 / 1(5 \%)$ & $2 / 0(2 \%)$ \\
Diarrhea & $11 / 0(11 \%)$ & $4 / 0(4 \%)$ \\
Anaemia & $3 / 0(3 \%)$ & $1 / 0(1 \%)$ \\
\hline
\end{tabular}

participate. The remaining 192 patients (CCRT, $\mathrm{n}=96$; $\mathrm{RT}, \mathrm{n}=96$ ) were entered into the study. 173 participants completed the efficacy assessment. 19 patients withdrew from the study. The major reasons for withdrawal were AEs, withdrawn consent, and failure to follow-up (Figure 1). The baseline characteristics of the patients were similar in the 2 treatment arms (Table 1 ).

The median number of treatment cycles was three (range 1-5) for CCRT, the duration of which was 11 weeks; and three (range 1-5) for RT, the duration of which was 10 weeks. The main reasons for discontinuation of treatment were AEs [CCRT versus RT, 6/96 (6.2\%) versus 4/96 (4.2\%)], consent withdrawal [3/96 (3.1\%) versus $2 / 96$ $(2.1 \%)]$, failure to follow-up [1/96 (1.0\%) versus $1 / 96$ $(1.0 \%)]$, and other reasons [1/96 (1.0\%) versus $1 / 96$ $(1.0 \%)]$.

The overall response rate as determined by the RECIST criteria, was $67 \%$ for CCRT $(n=96)$ and $53 \%$ for RT $(\mathrm{n}=96)$. The difference was statistically significant $(P<0.05$; Table 2$)$. The median overall survival was 68 months (range 3-85 months) and 61 months (range 4-83 months) for the CCRT and RT arms $(P=0.009)$, respectively (Figure 2). In addition, the median progression-free survival was 62 months and 51 months for the CCRT (range 3-83 months) and RT arms (range 4-81 months), respectively $(P=0.025$; Figure 3$)$.

Table 1 Baseline characteristics of participants at trial entry: ITT population

\begin{tabular}{|c|c|c|c|c|}
\hline & Variable & $\operatorname{CCR}(n=96)$ & RT $(n=96)$ & $P$ value \\
\hline Age, yrs: mean (SD) & & $46.5(14.1)$ & $46.2(13.9)$ & 0.9 \\
\hline Race & Asian (Chinese) & $96(100.0 \%)$ & $96(100.0 \%)$ & 1.0 \\
\hline \multicolumn{5}{|l|}{ FIGO stage } \\
\hline & $\| B$ & $39(40.6 \%)$ & $41(42.7 \%)$ & 0.8 \\
\hline & IIIA & $32(33.3 \%)$ & $31(32.3 \%)$ & 0.9 \\
\hline & $\| \mathrm{IIB}$ & $25(26.0 \%)$ & $24(25.0 \%)$ & 0.9 \\
\hline \multicolumn{5}{|l|}{ Tumor size (cm) } \\
\hline \multicolumn{5}{|l|}{ mean (SD) } \\
\hline & Median (range) & $4.1(2.3-6.4)$ & $4.0(2.2-6.3)$ & 0.9 \\
\hline & Average & $4.5(1.9)$ & $4.4(1.8)$ & 0.7 \\
\hline Deaths due to cervical carcinoma (n) & & $24(25.0 \%)$ & $33(34.4 \%)$ & 0.2 \\
\hline
\end{tabular}

Note: ITT, intent-to-treat; CCR, concurrent chemoradiation; RT, over radiotherapy; yrs, years; SD, standard deviation; FIGO, International Federation of Gynecology and Obstetrics. 


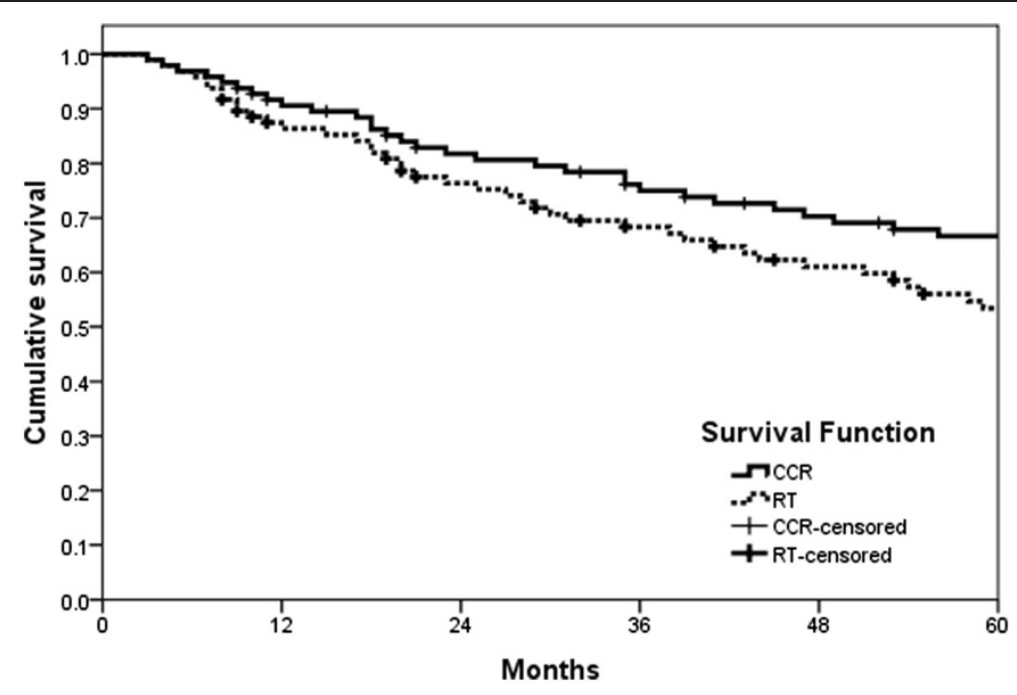

Figure 2 Overall survival.

AEs that occurred in each group are shown in Table 2. 96 CCRT and 96 RT patients were included. The incidence of major hematological toxicities was higher with CCRT than with RT. Grade 3 or 4 leukopenia was observed in 11/96 (11\%) of patients treated with CCRT versus $7 / 96$ (7\%) of patients treated with $\mathrm{RT}$, while the corresponding incidences of thrombocytopenia were $2 /$ $96(2 \%)$ versus $0 / 96(0 \%)$, respectively. The most common grade 3 or 4 non-hematological toxicities were diarrhea (CCRT versus RT, 11/96(11\%) versus 4/96 (4\%)), nausea $((5 / 96) 5 \%$ versus $2 / 96(2 \%))$, and anorexia (3/96 (3\%) versus $1 / 96(1 \%))$. There were no treatment-related deaths in either arm.

\section{Discussion}

Radiotherapy has been used as the only therapeutic option for patients with locally advanced cervical cancer in the past [34]. As $20-50 \%$ of patients with stage IIB and 50$75 \%$ with stage III tumors suffered a relapse, additional treatments [32], including chemotherapy [12-22] and hyperthermia [23] were incorporated in order to enhance the effects of radiotherapy. For example, cisplatin-based chemotherapy with concurrent radiotherapy has now taken center stage in the therapy of locally advanced uterine carcinoma [35].

A previous study from the Gynecological Oncology Group compared patients who underwent radiotherapy

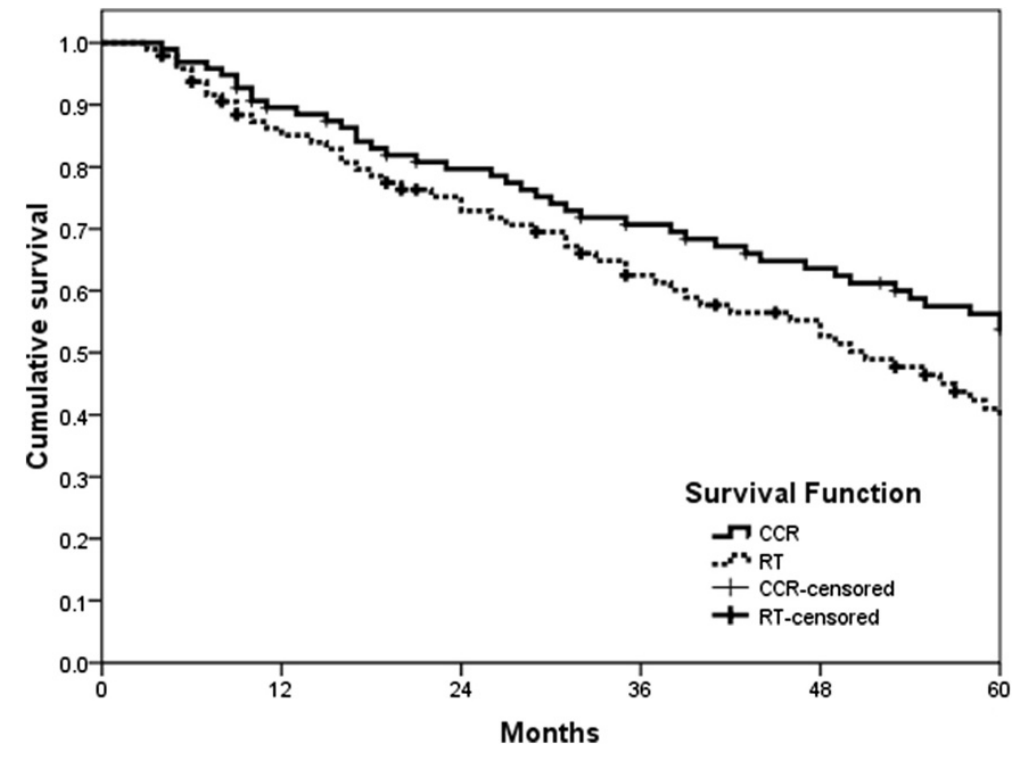

Figure 3 Progression-free survival. 
with cisplatin treatment to those receiving hydroxyurea. The study included participants with stage IIB-IVA cervical carcinoma. The group treated with both radiotherapy and cisplatin had a higher rate $(60 \%)$ of 5 -year survival in contrast to the group with hydroxyurea (34\%). The difference in survival was maintained after 10 years (53 and $34 \%$, respectively; $P<0.01$ ). In addition, patients with highly unfavorable pretreatment prognostic factors were closely monitored, especially those undergoing the 3 -weekly regimen. The 3.5-year survival rate was comparable to previous results.

In this study, CCRT also had a favorable safety profile. The overall frequency of AEs was similar in both arms and most side effects were not severe. The frequency of both drug-related AEs and AEs of severe intensity was higher in the CCRT arm than in the RT arm.

A previous publication concluded that when bulky disease was defined as tumors larger than $4 \mathrm{~cm}$, tumor size was also of prognostic importance in FIGO stage II cervical carcinomas [36]. In this study, there was no significant difference in the median and average sizes of tumor diameter between the 2 groups $(P=0.9$ and $P=0.7$ respectively), although tumor stages varied from IIB to IIIB. Tumor size was determined by pathological evaluation in the CCRT group and pretreatment MRI in the RT group.

Our study has several strengths. Firstly, the trial was randomized thereby reducing selection bias. Secondly, although there was no consensus regarding the dose appropriate for CCRT in Chinese patients with locally advanced cervical carcinoma, this trial suggested that our treatment was in the therapeutic range. Further studies with larger sample size and longer duration of CCRT are needed to further confirm the results of this study.

In conclusion, the results of this study show promising efficacy and a very acceptable toxicity profile for CCRT in Chinese patients with locally advanced cervical carcinoma. The follow-up period is still short, but the encouraging clinical and pathological results warrant further investigation.

\section{Competing interests}

The authors declare that they have no competing interests.

\section{Authors' contributions}

$\mathrm{SH}$ conceived of the study, participated in the coordination and design of the study, performed. ZL performed the statistical analysis and wrote the paper. $\mathrm{ZL}$, SY, LL and SH carried out the clinical assessment and participated in most parts of the study. All authors read and approved the final manuscript.

\section{Acknowledgements}

This study was funded by Heilongjiang Province Science Foundation for Youths (Grant No. QC2012C106).

Received: 3 August 2014 Accepted: 11 September 2014 Published: 22 September 2014

\section{References}

1. Maduro JH, Pras E, Willemse PH, de Vries EG: Acute and long-term toxicity following radiotherapy alone or in combination with chemotherapy for locally advanced cervical cancer. Cancer Treat Rev 2003, 29:471-488.
2. Kirwan JM, Symonds P, Green JA, Tierney J, Collingwood M, Williams CJ: A systematic review of acute and late toxicity of concomitant chemoradiation for cervical cancer. Radiother Oncol 2003, 68:217-226.

3. Denton AS, Bond SJ, Matthews S, Bentzen SM, Maher EJ, UK Link Gynaecology-Oncology Group: National audit of the management and outcome of carcinoma of the cervix treated with radiotherapy in 1993. Clin Oncol (R Coll Radiol) 2000, 12:347-353.

4. Lajer H, Thranov IR, Skovgaard LT, Engelholm SA: Late urologic morbidity in 177 consecutive patients after radiotherapy for cervical carcinoma: a longitudinal study. Int J Radiat Oncol Biol Phys 2002, 54:1356-1361.

5. National Cancer Institutes: Guidelines gynaecologic tumours: cervical carcinoma [Internet]. Bethesda, MD: National Cancer Instututes; 2004. [cited 2011 Jun 20]. Available from: http://www.cancer.gov.

6. Thomas GM: Improved treatment for cervical cancer: concurrent chemotherapy and radiotherapy. N Engl J Med 1999, 340:1198-1200.

7. King M, McConkey C, Latief TN, Hartley A, Fernando I: Improved survival after concurrent weekly cisplatin and radiotherapy for cervical carcinoma with assessment of acute and late side-effects. Clin Oncol (R Coll Radiol) 2006, 18:38-45.

8. Einarsson Il, Cohen SL, Puntambekar S: Orifice-assisted small-incision surgery: case series in benign and oncologic gynecology. J Minim Invasive Gynecol 2012, 19(3):365-368.

9. Höckel M, Horn LC, Einenkel J: (Laterally) extended endopelvic resection: surgical treatment of locally advanced and recurrent cancer of theuterine cervix and vagina based on ontogenetic anatomy. Gynecol Oncol 2012, 127(2):297-302.

10. Liu SP, Huang $X, K e ~ G H$, Huang XW: 3D radiation therapy or intensitymodulated radiotherapy for recurrent and metastatic cervicalcancer: the Shanghai Cancer Hospital experience. PLoS One 2012, 7(6):e40299.

11. Forrest J, Presutti J, Davidson M, Hamilton P, Kiss A, Thomas G: A dosimetric planning study comparing intensity-modulated radiotherapy with four-field conformal pelvic radiotherapy for the definitive treatment of cervical carcinoma. Clin Oncol (R Coll Radiol) 2012, 24(4):e63-e70.

12. Muderspach LI, Curtin JP, Roman LD, Gebhardt JA, Klement V, Qian D, Morrow CP, Felix JC, Formenti SC, Muggia FM: Carboplatin as a radiation sensitizer in locally advanced cervical cancer: a pilot study. Gynecol Oncol 1997, 65(2):336-342.

13. Thigpen JT, Blessing JA, DiSaia PJ, Fowler WC Jr, Hatch KD: A randomized comparison of a rapid versus prolonged ( $24 \mathrm{hr}$ ) infusion of cisplatin in therapy of squamous cellcarcinoma of the uterine cervix: a Gynecologic Oncology Group study. Gynecol Oncol 1989, 32(2):198-202.

14. Kudelka AP, Winn R, Edwards CL, Downey G, Greenberg H, Dakhil SR, Freedman RS, LoCoco S, Umbreit J, Delmore JE, Arbuck S, Loyer E, Gacrama $P$, Fueger $R$, Kavanagh JJ: An update of a phase II study of paclitaxel in advanced or recurrent squamous cell cancer of the cervix. Anticancer Drugs 1997, 8(7):657-661.

15. Puls LE, Phillips B, Schammel C, Hunter JE, Griffin D: A phase I-II trial of weekly topotecan in the treatment of recurrent cervical carcinoma. Med Oncol 2010, 27(2):368-372.

16. Schilder RJ, Blessing JA, Morgan M, Mangan CE, Rader JS: Evaluation of gemcitabine in patients with squamous cell carcinoma of the cervix: a Phase II study of the gynecologic oncology group. Gynecol Oncol 2000, 76(2):204-207.

17. Vallejo CT, Machiavelli MR, Pérez JE, Romero AO, Bologna F, Vicente $H$, Lacava JA, Ortiz EH, Cubero A, Focaccia G, Suttora G, Scenna M, Boughen JM, Leone BA: Docetaxel as neoadjuvant chemotherapy in patients with advanced cervical carcinoma. Am J Clin Oncol 2003, 26(5):477-482.

18. Buxton EJ, Blackledge G, Mould JJ, Monaghan J, Paterson M, Tobias J, Alcock C, Spooner D, Meanwell CA: The role of ifosfamide in cervical cancer. Semin Oncol 1989, 16(1 Suppl 3):60-67.

19. Colombo A, Landoni F, Cormio G, Barni S, Maneo A, Nava S, Pellegrino A, Placa F, Mangioni C: Concurrent carboplatin/5FU and radiotherapy compared to radiotherapy alone in locally advanced cervical carcinoma: a case-control study. Tumori 1997, 83(6):895-899.

20. Irvin WP, Price FV, Bailey H, Gelder M, Rosenbluth R, Durivage HJ, Potkul RK: A phase II study of irinotecan (CPT-11) in patients with advanced squamous cell carcinoma of the cervix. Cancer 1998, 82(2):328-333.

21. Thigpen T, Blessing JA, Gallup DG, Maiman M, Soper JT: Phase II trial of mitomycin- $C$ in squamous cell carcinoma of the uterine cervix: a Gynecologic Oncology Group study. Gynecol Oncol 1995, 57(3):376-379 
22. Tewari KS, Sill MW, Long HJ 3rd, Penson RT, Huang H, Ramondetta LM, Landrum LM, Oaknin A, Reid TJ, Leitao MM, Michael HE, Monk BJ: Improved survival with bevacizumab in advanced cervical cancer. $N$ Engl J Med 2014, 370(8):734-743.

23. van der Zee J, González González D, van Rhoon GC, van Dijk JD, van Putten WL, Hart AA: Comparison of radiotherapy alone with radiotherapy plus hyperthermia in locally advanced pelvic tumours: a prospective, randomised, multicentre trial. Dutch Deep Hyperthermia Group. Lancet 2000, 355(9210):1119-1125.

24. Schefter TE, Winter K, Kwon JS, Stuhr K, Balaraj K, Yaremko BP, Small W Jr, Gaffney DK: A phase II study of bevacizumab in combination with definitive radiotherapy and cisplatin chemotherapy in untreated patients with locally advanced cervical carcinoma: preliminary results of RTOG 0417. Int J Radiat Oncol Biol Phys 2012, 83(4):1179-1184.

25. Giorda G, Boz G, Gadducci A, Lucia E, De Piero G, De Paoli A, Innocente R, Trovò M, Sorio R, Campagnutta E: Multimodality approach in extra cervical locally advanced cervical cancer: chemoradiation, surgery and intra-operative radiation therapy: A phase II trial. Eur J Surg Oncol 2011, 37(5):442-447.

26. Chassagne D, Sismondi P, Horiot JC, Sinistrero G, Bey P, Zola P, Pernot M, Gerbaulet A, Kunkler I, Michel G: A glossary for reporting complications of treatment in gynecological cancers. Radiother Oncol 1993, 26:195-202.

27. Ryu SY, Lee WM, Kim K, Park SI, Kim BJ, Kim MH, Choi SC, Cho CK, Nam BH, Lee ED: Randomized clinical trial of weekly vs. triweekly cisplatin-based chemotherapy concurrent with radiotherapy in the treatment of locally advanced cervical cancer. Int J Radiat Oncol Biol Phys 2011, 81(4):e577-e581.

28. Green JA, Kirwan JM, Tierney JF, Symonds P, Fresco L, Collingwood M, Williams CJ: Survival and recurrence after concomitant chemotherapy and radiotherapy for cancer of the uterine cervix: a systematic review and meta-analysis. Lancet 2001, 358:781-786.

29. Chemoradiotherapy for Cervical Cancer Meta-Analysis Collaboration: Reducing uncertainties about the effects of chemoradiotherapy for cervical cancer: a systematic review and meta-analysis of individual patient data from 18 randomized trials. J Clin Oncol 2008, 26:5802-5812.

30. Lukka H, Hirte H, Fyles A, Lukka H, Hirte H, Fyles A, Thomas G, Elit L, Johnston M, Fung MF, Browman G, Cancer Care Ontario Practice Guidelines Initiative Gynecology Disease Site Group: Concurrent cisplatin-based chemotherapy plus radiotherapy for cervical cancer: a meta-analysis. Clin Oncol (R Coll Radiol) 2002, 14:203-212.

31. Tan LT, Russell S, Burgess L: Acute toxicity of chemo-radiotherapy for cervical cancer: the Addenbrooke's experience. Clin Oncol (R Coll Radiol) 2004, 16:255-260.

32. Therasse P, Arbuck SG, Eisenhauer EA, Therasse P, Arbuck SG, Eisenhauer EA, Wanders J, Kaplan RS, Rubinstein L, Verweij J, Van Glabbeke M, van Oosterom AT, Christian MC, Gwyther SG: New guidelines to evaluate the response to treatment in solid tumors. European Organization for Research and Treatment of Cancer, National Cancer Institute of the United States, National Cancer Institute of Canada. J Natl Cancer Inst 2000, 92:205-216.

33. Cancer Therapy Evaluation Program: Common Terminology Criteria for Adverse Events V3.0. 2006.

34. Coia L, Won M, Lanciano R, Marcial VA, Martz M, Hanks G: The patterns of care outcome study for cancer of the uterine cancer: Results of the second national practice survey. Cancer 1990, 66:2451-2456.

35. Rose PG, Ali S, Watkins E, Thigpen JT, Deppe G, Clarke-Pearson DL, Insalaco S, Gynecologic Oncology Group: Long-term follow-up of a randomized trial comparing concurrent single agent cisplatin, cisplatin-based combination chemotherapy, or hydroxyurea during pelvic irradiation for locally advanced cervical cancer: A Gynecologic Oncology Group Study. J Clin Oncol 2007, 25:2804-2810.

36. Horn LC, Fischer U, Raptis G, Bilek K, Hentschel B: Tumor size is of prognostic value in surgically treated FIGO stage II cervical cancer. Gynecol Oncol 2007, 107:310-315.

doi:10.1186/1748-717X-9-212

Cite this article as: Li et al:: A comparison of concurrent

chemoradiotherapy and radiotherapy in Chinese patients with locally advanced cervical carcinoma: a multi-center study. Radiation Oncology 2014 9:212

\section{Submit your next manuscript to BioMed Central and take full advantage of:}

- Convenient online submission

- Thorough peer review

- No space constraints or color figure charges

- Immediate publication on acceptance

- Inclusion in PubMed, CAS, Scopus and Google Scholar

- Research which is freely available for redistribution 